\title{
Secreted Spitz triggers the DER signaling pathway and is a limiting component in embryonic ventral ectoderm determination
}

\author{
Ronen Schweitzer, ${ }^{1}$ Miriam Shaharabany, ${ }^{1}$ Rony Seger, ${ }^{2}$ and Ben-Zion Shilo ${ }^{1,3}$ \\ Departments of ${ }^{1}$ Molecular Genetics and Virology and ${ }^{2}$ Membrane Research and Biophysics, Weizmann Institute of Science, \\ Rehovot 76100, Israel
}

The spitz gene encoding a TGF- $\alpha$ homolog, has been shown to affect a subset of developmental processes that are similar to those regulated by DER, the Drosophila EGF receptor homolog. This work demonstrates that Spitz triggers the DER signaling cascade. Addition of a secreted, but not the membrane-associated form of Spitz to S2 Drosophila cells expressing DER gives rise to a rapid tyrosine autophosphorylation of DER. Following autophosphorylation, DER associates with the Drk adapter protein. Consequently, activation of MAP kinase is observed. The profile of MAP kinase activation provides a quantitative assay for DER activation. A dose response between the levels of Spitz and MAP kinase activity was observed. The secreted Spitz protein was expressed in embryos to assess its biological activity. An alteration in cell fates was observed in the ventral ectoderm, such that lateral cells acquired the ventral-most fates. The result indicates that graded activation of the DER pathway may normally give rise to a repertoire of discrete cell fates in the ventral ectoderm. Spatially restricted processing of Spitz may be responsible for this graded activation. The Rhomboid (Rho) and Star proteins were suggested, on the basis of genetic interactions, to act as modulators of DER signaling. No alteration in DER autophosphorylation or the pattern of MAP kinase activation by secreted Spitz was observed when the Rho and Star proteins were coexpressed with DER in S2 cells. In embryos mutant for rho or Star the ventralizing effect of secreted Spitz is epistatic, suggesting that Rho and Star may normally facilitate processing of the Spitz precursor.

[Key Words: Drosophila; signal transduction; receptor tyrosine kinase; EGF receptor; DER; spitz group]

Received February 23, 1995; revised version accepted May 10, 1995.

DER, the Drosophila epidermal growth factor (EGF) receptor homolog, has been shown to fulfill multiple roles during development. In the embryo these roles include the establishment of ventral ectodermal fates (Raz and Shilo 1993), differentiation of the midline glial cells (Raz and Shilo 1992), Malpighian tubule development (Baumann and Skaer 1993), germ-band retraction, and head development (Schejter and Shilo 1989; Clifford and Schüpbach 1990). During imaginal disc development, DER was shown to be essential for proliferation of disc cells (Clifford and Schüpbach 1990), vein and bristle formation in the wing disc (Diaz-Benjumea and Garcia-Bellido 1990|, and the differentiation of photoreceptors in the eye disc (Baker and Rubin 1989; Xu and Rubin 1993). Finally, during oogenesis DER is a central player in the reception of information from the oocyte dictating dorsal follicle cell fate determination (Price et al. 1989).

The wide range of processes in which DER participates provides a large repertoire of situations to test for similarities in phenotypes and to examine genetic interactions with other genes participating in the same signal-

${ }^{3}$ Corresponding author. ing pathway. It has allowed the identification of a group of genes that form a DER signaling cassette. Some are specific to the DER pathway, whereas others are also essential for the signaling of other receptor tyrosine kinases. The latter class includes, downstream of the receptor, the canonical Ras/Raf pathway. A variety of observations support this conclusion: Clones homozygous for mutations in the genes encoding Drk, Sos, Ras, Raf, Dsorl (MAPKK or MEK), and MAP kinase (MAPK) give rise to phenotypes similar to mutant DER clones in the wing disc (Diaz-Benjumea and Hafen 1994). In the eye disc, mutations in Drk, Sos, and Dras1 act as dominant suppressors of the dominant DER mutant phenotype Ellipse (Rogge et al. 1991; Simon et al. 1991, 1993; Olivier et al. 1993). In the embryo, elimination of the maternal and zygotic contribution of Sos or Draf gives rise to phenotypes similar to the DER flb null phenotype (Lu et al. 1993; Melnick et al. 1993|. Finally, gain-of-function mutations in raf give rise to dorsalized follicle cells (Brand and Perrimon 1994), whereas loss-of-function mutations in Dmek result in ventralized egg chambers (Hsu and Perrimon 1994), a phenotype similar to the torpedo lossof-function DER mutation. The cytoplasmic elements 
relaying DER signaling are essential. However, they are not unique to the DER signaling cassette and are employed in the signaling of other receptor tyrosine kinases as well, for example, Sevenless, Torso and Breathless. Therefore, it is unlikely that their distribution may play a role in determining the level or specificity of the DER signaling pathway.

A second class of genes participating in DER signaling seems to be unique to the DER signaling cassette. The spitz group was defined on the basis of phenotypic similarities and genetic interactions (Mayer and NüssleinVolhard 1988; Klämbt et al. 1991). It contains four proteins that are relevant to this context: Pointed is a transcription factor containing a conserved Ets domain; one of the two splicing alternatives contains canonical MAPK phosphorylation sites and was shown to be a cardinal target for the DER signaling pathway in the midline glial cells (Klämbt 1993; Klaes et al. 1994); and Rhomboid (Rho) and Star are two novel membrane proteins. Rho contains seven putative transmembrane domains (Bier et al. 1990), and Star contains a single transmembrane domain (Kolodkin et al. 1994).

The way in which Rho and Star interact with the DER pathway is not clear. On the basis of limited data, they are envisaged as modulators of the signaling pathway rather than as elements that are crucial for the actual signal transduction. For example, although both $D E R$ and $r$ ho have no maternal transcripts in the embryo, the $D E R$ null phenotype, $f l b$, is more severe than the rhomboid null phenotype. A wide range of genetic interactions identified in the embryo and eye and wing discs make a compelling argument for the functional connection between Rho, Star, and DER (Raz and Shilo 1993; Sturtevant et al. 1993; Freeman 1994; Noll et al. 1994). Moreover, the restricted expression of rho in different contexts may play a central role in localized modulation of DER signaling. For example, rho is expressed in the dorsal-anterior follicle cells. Ectopic expression of Rho in all follicle cells gives rise to dorsalized cell fates but only when a functional DER signaling pathway is present. Conversely, a reduction in rho expression in these cells leads to ventralized cell fates, similar to the situation in which the signaling of the DER pathway is reduced (Ruohola-Baker et al. 1993).

The fourth member of the spitz group is Spitz itself. It has been shown to encode a protein belonging to the TGF- $\alpha$ family, suggesting that it is a potential ligand for DER (Rutledge et al. 1992). Spitz is a protein of 230 amino acids containing a signal peptide, a transmembrane domain, and a single EGF motif in the extracellular domain (Fig. 1). A dibasic signal located between the EGF and transmembrane domains is a potential cleavage site, suggesting that like TGF- $\alpha$, the Spitz precursor may be cleaved to generate a secreted ligand. The expression of spitz is not highly restricted. It has a maternal transcript in the embryo and is later expressed ubiquitously in all embryonic tissues, with enrichment in the procephalic region, ventral midline, and the mesoderm (Rutledge et al. 1992). In the eye disc it was shown to be expressed posterior to the morphogenetic furrow (Tio et
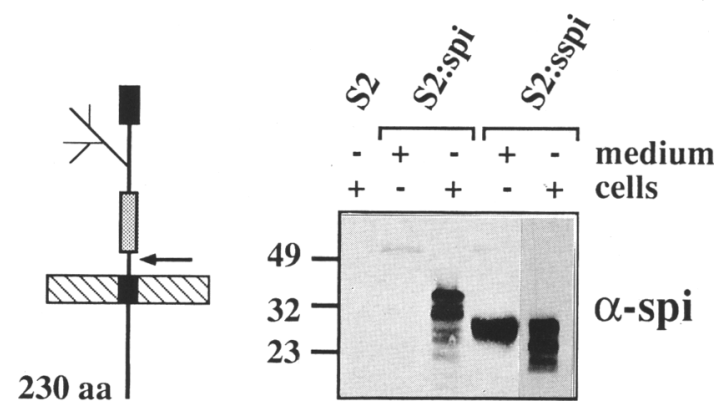

Figure 1. Expression of membrane-associated and soluble Spitz proteins in S2 cells. Schematic representation of the Spitz protein. (Stippled region) EGF domain; (arrow) putative cleavage site; (solid regions) signal peptide and transmembrane domains; $\mathrm{N}$-linked glycosylation site is marked. Untransfected S2 cells do not express Spitz. Stable S2 cell lines expressing the full-length Spitz protein (S2:spi) and a truncated, secreted form of Spitz (S2:sspi) under regulation of the metallothionein promoter were established. Several Spitz immunoreactive bands are detected in Western blots of lysates from these cells. Time course of protein induction and tunicamycin pretreatment of the cells were used to show that in both cell lines the lower bands represent glycosylation intermediates of the mature Spitz proteins (data not shown|. Testing conditioned medium of S2:sspi cells with antibodies recognizing the Spitz extracellular domain shows that Spitz is secreted by the S2:sspi cells, whereas in conditioned medium of S2:spi cells there is no Spitz protein. This indicates that the full-length Spitz is not cleaved in S2:spi cells.

al. 1994). Genetic interactions between DER and spitz were observed in the embryo and in the eye disc ( $R a z$ and Shilo 1993; Freeman 1994; Tio et al. 1994). These observations implicated Spitz as a potential ligand for DER in several developmental phases.

Another TGF- $\alpha$-like molecule, Gurken, has also been implicated as a DER ligand (Neuman-Silberberg and Schüpbach 1993). gurken transcripts are localized to the dorsal-anterior corner of the oocyte, and the protein is likely to provide a localized source of DER activation in the follicle cells. Multiple copies of gurken give rise to dorsalized egg chambers (Neuman-Silberberg and Schüpbach 1994). In Caenorhabditis elegans, Lin 3, a TGF- $\alpha$ homolog has been implicated in the activation of Let-23, the EGF receptor homolog (Hill and Sternberg 1992). Again, a localized source of ligand expressed in the anchor cell, relays the information to the underlying ectodermal cells and induces determination of vulval cells.

On the basis of the biological and structural data for the interaction between Spitz and DER, it was crucial to test whether Spitz is a ligand capable of activating DER. In this paper we demonstrate that the secreted, but not the membrane-associated, form of Spitz is capable of triggering the DER signaling pathway. A dose response between the levels of Spitz and MAP kinase activity was observed. This may represent a situation where intermediate cell fates can be induced by restricted processing or presentation of the ligand. Expression of secreted Spitz in the embryo gave rise to the acquisition of ectopic ventral 
cell fates. Finally, in cells, the triggering of DER by Spitz can occur in the absence of Rho or Star, raising the possibility that their role in DER signaling may be restricted to the processing of the Spitz precursor. In rho or Star mutant embryos, the ventralizing effect of secreted Spitz is epistatic.

\section{Results}

Expression of Spitz and DER in S2 cells

Drosophila Schneider S2 cells were used to study DERSpitz interactions. Because they do not normally express the endogenous Spitz protein (Fig. 1), the cells were transfected with constructs encoding either full-length Spitz (to generate S2:spi cells), or a secreted Spitz protein in which a termination codon was used to replace the dibasic putative cleavage signal (S2:sspi). The constructs were placed under control of the inducible metallothionein promoter. Following induction, the mature Spitz proteins of 37 and $27 \mathrm{kD}$ could be detected in the S2:spi and S2:sspi cells, respectively. Several processing intermediates were detected in cell extracts (Fig. 1). The processing intermediates in both cell lines were eliminated by deglycosylation of the cell extracts (data not shown), indicating that Spitz processing in S2:spi cells consisted of several glycosylation steps. The full-length Spitz protein is not cleaved in the $S 2$ :spi cells, as the protein cannot be detected in the medium. In contrast, significant amounts of the mature form of secreted Spitz are detected in the medium of the S2:sspi cells (Fig. 1).

The DER gene was shown to have two splicing alternatives generated by different 5 ' exons (Scheiter et al. 1986). The amino-terminal sequences of the resulting DER proteins, termed type I and type II, include 101 and 52 unique amino acids, respectively. S2 cells do not express the endogenous DER (Fig. 2). The experiments described below were carried out in parallel on S2 cell lines expressing type I DER (S2:DER1) or type II DER (S2:DER2) under regulation of the metallothionein promoter (Fig. 2). Immunohistochemistry demonstrated that the two lines displayed some of the DER protein on the cell surface (data not shown).

\section{Spitz triggers DER autophosphorylation}

The initial event following activation of the EGF receptor is autophosphorylation of tyrosine residues on the carboxy-terminal tail (Ullrich and Schlessinger 1990). Overexpression in either of the DER-expressing lines resulted in spontaneous tyrosine phosphorylation of the DER protein (data not shown), possibly because of overcrowding of DER molecules on the cell surface that leads to spontaneous dimerization of receptor molecules. However, after induction for only $3 \mathrm{hr}$ with lower concentrations of the inducer (see Materials and methods), a minimal level of spontaneous phosphorylation was obtained on DER. Under these conditions, type I DER in S2:DER1 cells displayed a higher tendency for spontaneous phosphorylation than type II DER (Fig. 2). Addition

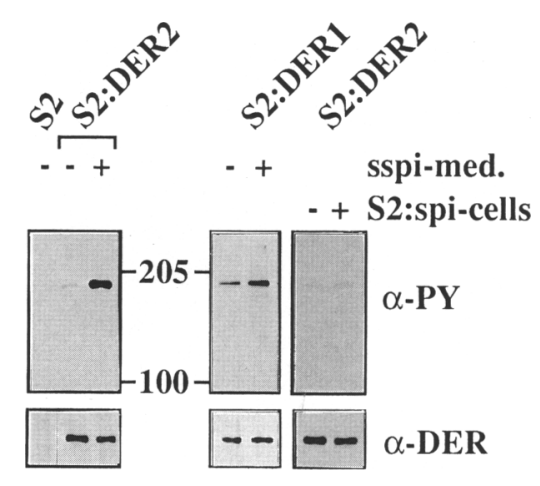

Figure 2. DER tyrosine autophosphorylation is triggered by the secreted Spitz. Tyrosine phosphorylation of immunoprecipitated DER was assayed in Western blots probed with anti-phosphotyrosine antibodies. Parallel blots were probed with antiDER antibodies to ensure that equal amounts of the immunoprecipitated DER were used. Background levels of tyrosine phosphorylation can be detected on DER even before adding the secreted Spitz; however, a dramatic increase in the level of tyrosine phosphorylation is detected within $1 \mathrm{~min}$ after the secreted Spitz was added. Both types of DER proteins (in the S2:DER 1 and S2:DER2 cell lines) were activated by secreted Spitz. Activation of the type II DER is, however, much more pronounced. Experiments with the membrane-associated, fulllength Spitz did not lead to activation of the receptor. Overlaying S2:DER2 cells by induced S2:spi $|+|$ cells or by S2 cells in control $(-)$ for 10 min did not change the levels of tyrosine phosphorylation on the receptor. Similar results were obtained for S2:DER1. In addition, utilization of membrane preparations of $S 2$ :spi instead of the intact cells, to ensure better accessibility of the ligand to the receptor, did not activate both forms of DER (data not shown).

of S2-conditioned medium did not affect the level of phosphotyrosine residues on DER. However, application of conditioned medium containing secreted Spitz to S2:DER2 cells resulted, within $1 \mathrm{~min}$, in a dramatic increase in the phosphotyrosine content of DER (Fig. 2). This level of phosphorylation was maintained for at least $30 \mathrm{~min}$ (data not shown). Activation of DER in S2:DER1 cells was induced with similar kinetics but appeared to be less pronounced (Fig. 2). DER is homologous to the vertebrate EGF receptor family (Livneh et al. 1985). Ligands of these receptors which are all homologous to Spitz, including EGF, TGF- $\alpha$ and neu differentiation factor (NDF), did not induce the tyrosine kinase activity of DER (data not shown).

The cell culture experiments described above demonstrate that secreted Spitz is a ligand of DER. The overlapping embryonic expression patterns of spitz and $D E R$ are also compatible, however, with a biological activity contributed by membrane-associated Spitz (Rutledge et al. 1992; Zak et al. 1990). Furthermore, membrane-associated TGF- $\alpha$ has been shown to activate the EGF receptor (Wong et al. 1989). Therefore, it was of interest to examine the ability of membrane-associated Spitz to trigger DER. Several methods were utilized in an attempt to activate DER, including overlaying the DERexpressing cells with an excess of S2:spi cells or mem- 
brane preparations of these cells. In addition, a pellet of DER cells was generated with an excess of S2:spi cells. However, no activation of DER was observed in S2:DER2 cells (Fig. 2) or S2:DER1 cells (data not shown).

\section{DER/Drk association}

We wanted to determine whether downstream elements in the DER signaling cascade are also activated by secreted Spitz binding. A universal signaling mechanism for activated receptor tyrosine kinases has been identified: An adapter molecule (human Grb2, C. elegans Sem5, and Drosophila Drk), containing SH2 and $\mathrm{SH} 3$ domains (Lowenstein et al. 1992; Clark et al. 1992; Olivier et al. 1993; Simon et al. 1993), mediates the interaction of the phosphorylated receptor with downstream elements such as Sos (Buday and Downward 1993; Egan et al. 1993; Li et al. 1993; Rozakis-Adcock et al. 1993). The Drosophila Drk protein was shown to bind the activated Sevenless and was genetically implicated in Sevenless and DER signaling (Olivier et al. 1993; Simon et al. 1993|. Following addition of secreted Spitz to S2:DER2 cells, the Drk protein was immunoprecipitated from the cell lysates, using Drk-specific antibodies. Coprecipitation of DER was observed by probing with antiDER and anti-phosphotyrosine antibodies (Fig. 3). Coimmunoprecipitated DER is more readily detectable with the anti-phosphotyrosine antibodies, as the phosphorylated form of DER is preferentially associated with Drk.

\section{Activation of MAP kinase}

A central step in the cytoplasmic signaling cascade of receptor tyrosine kinases is the activation of MAPK. A single MAPK gene, termed rolled, was identified in Drosophila (Biggs and Zipursky 1992; Biggs et al. 1994;

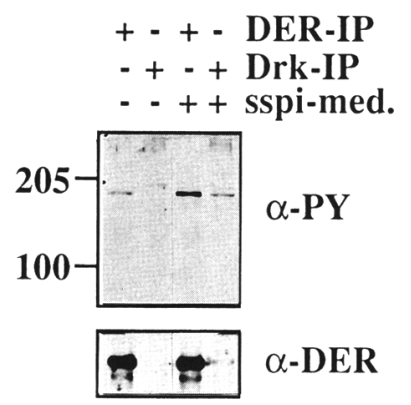

Figure 3. Activation-dependent association of DER with the Drk adapter molecule. Following activation by the secreted Spitz, cell lysates were immunoprecipitated by anti-DER and anti-Drk antibodies. The precipitates were subjected to a Western blot and probed with anti-DER and anti-phosphotyrosine antibodies. DER is precipitated by anti-Drk antibodies after incubation with the soluble Spitz medium $(+\mid)$ but not after incubation with the control S2 conditioned medium $(-1$. Only a small fraction of the DER protein is precipitated by the anti-Drk antibodies, whereas the Drk protein was completely precipitated in the experiment (data not shown).
Brunner et al. 1994). Mutations in this gene gave rise to phenotypes similar to those of mutations in DER (DiazBenjumea and Hafen 1994) or sevenless (Brunner et al. 1994), suggesting that it is the only MAPK-activated by RTK pathways in Drosophila. In S2 cells MAPK can be detected as a 44-kD protein (Biggs and Zipursky 1992). MAPK activation in S2 cells was assayed by monitoring the phosphorylation of myelin basic protein (MBP) by a fraction of cytosolic extract enriched for MAPK (Seger et al. 1994). Following addition of secreted Spitz-conditioned medium to the DER-expressing cells, an elevation in MAPK activity was observed, peaking at 7-10 $\mathrm{min}$ and declining within 30-60 min (Fig. 4A).

MAPK activity serves as a sensitive quantitative assay to monitor the level of activation of the DER pathway. The conditioned medium contains an excess of Spitz, as a 10-fold dilution of the medium resulted in similar levels of DER autophosphorylation (data not shown). This assay was used further to identify the range of Spitz dilutions in which DER signaling would decline. By diluting the conditioned medium 50- to 100 -fold, a reduction in DER autophosphorylation was observed (data not shown). These dilutions were then used to test the level of MAPK activation. MAPK activity in each case was monitored after $7.5 \mathrm{~min}$. Medium diluted 50 - to 200 -fold gave rise to a gradual reduction in the level of activated MAPK (Fig. 4B). Conditioned medium diluted 75 -fold gave rise to the typical kinetics of MAPK activation, but the peak of activity was $\sim 60 \%$ of the maximal peak (Fig. 4A). This result demonstrates that under limiting Spitz concentrations, intermediate levels of activation of the signaling pathway can be obtained. Different activation levels in the DER-induced cells may induce distinct cell fates during development, as described below.

\section{Activity of secreted Spitz in embryos}

Following the demonstration that only the secreted form of Spitz can trigger DER in the S2 cell assay, it was important to determine whether it also represents the active form in vivo. Transgenic lines were generated by contructs in which the wild-type spitz cDNA, or the cDNA with the termination following the EGF domain, were inserted downstream to the GAL4 upstream activating sequence (UAS) sequence (Brand and Perrimon 1993). Although the generation of fly lines containing the wild-type cDNA (UAS-mSpi flies) was standard, the injected UAS-secreted Spitz construct appeared to be toxic to the embryos. Thus, only a small number of embryos developed following injection, probably because of transient expression from the injected plasmid. The survival rate was improved by reducing the concentration of injected plasmid, and transgenic lines (UAS-sSpi flies) were recovered from the surviving embryos at a normal frequency.

DER is crucial for cell fate determination in the ventral ectoderm (Raz and Shilo 1993). In embryos mutated for DER or the spitz group genes, the ventral ectoderm is reduced. Ventral ectoderm defects can be demonstrated at stage 11, by following specific markers: Fasciclin III 


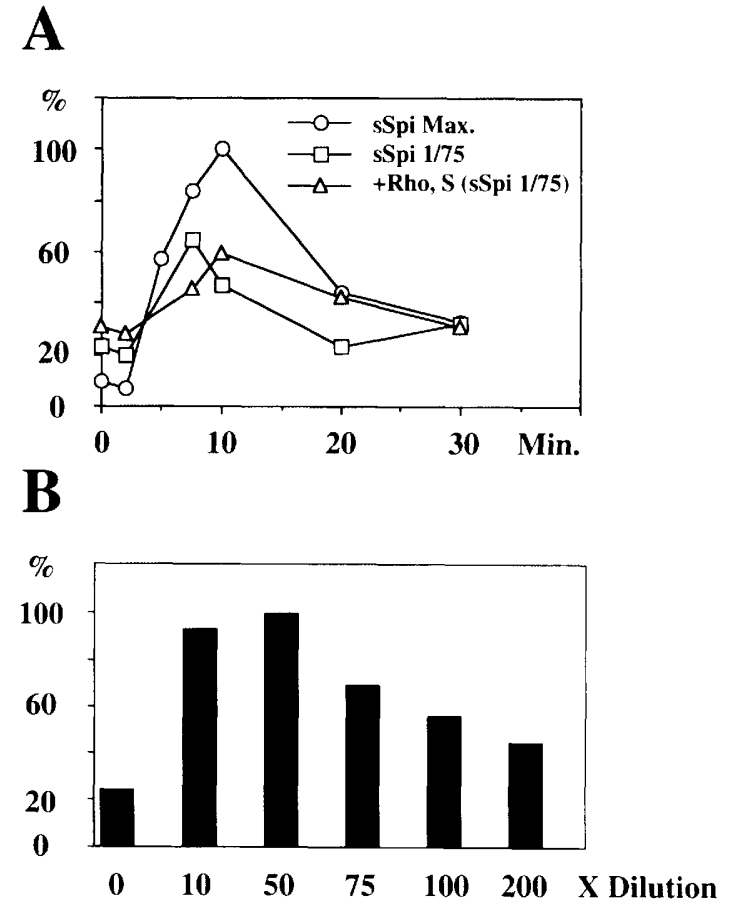

Figure 4. Activation of MAPK by secreted Spitz. $(A)$ DER-expressing cells were treated with conditioned medium from S2:sSpi cells. At the indicated time points, cells were harvested and cytosolic extracts were prepared as described in Materials and methods. The extracts were loaded on DEAE-cellulose columns, MAPK activity was eluted by a salt gradient, and its activity was determined by MBP phosphorylation. Every time point is an average of two independent cell lysates. Activation of DER by limiting Spitz concentrations resulted in a lower maximum but a similar overall pattern of MAPK activation. When the same limiting secreted Spitz concentration was applied to S2:D2RS cells expressing Rho and Star under HSP70 regulation (1.5 hr after heat shock), a similar kinetics of MAPK activation was observed. Heat shock does not affect the kinetics of MAPK activation in the parental S2:DER2f cells (not shown). (B) To determine the effect of reduced Spitz concentrations on MAPK activation, different dilutions of the S2:sSpi medium were used to activate S2:DER2f cells. MAPK activity in each case was monitored after $7.5 \mathrm{~min}$. Again, every point is an average of two independent cell lysates. Medium diluted 50- to 200 -fold gave rise to a gradual reduction in the level of activated MAPK. Similar results were obtained when the level of DER autophosphorylation was monitored (data not shown).

(Fas III) protein, expressed in the four to five ventralmost cell rows on each side of the midline (Patel et al. 1987), and Otd, which is normally detected in the one to two ventral-most cell rows (Wieschaus et al. 1992). Both markers are not expressed in these mutants (Raz and Shilo 1993; M. Golembo and B.-Z. Shilo, in prep.).

To study the effects of overexpressing the Spitz protein in the ventral ectoderm, the UAS-mSpi and UAS-sSpi flies were crossed to flies expressing the Gal4 protein in the ventral ectoderm. The Krüppel $(\mathrm{Kr})-G A L 4$ line is a useful inducer for this purpose. When crossed to UASlac $Z$ flies, expression of $\beta$-Gal is detected only in para- segments $\mathrm{T} 2-\mathrm{A} 4$ (data not shown). Therefore, $\mathrm{T} 1$ and A5-A8, which are not affected, serve as internal controls for possible effects in the same embryo. Expression of the Spitz precursor (from the UAS-mSpi flies) resulted in a partially penetrant embryonic lethality. However, the morphology of the cuticle (Fig. 5A) and the pattern of Fas III expression (Fig. 5B) were not affected. The biological activity of the UAS-mSpi construct was verified by its ability to rescue ventral Fas III expression in homozygous spitz ${ }^{\mathrm{OE} 92}$ mutant embryos, following induction by the 69B-GAL4 construct (data not shown).

In contrast to the ubiquitous expression of the Spitz precursor, expression of the secreted Spitz driven by the same inducer gave rise to ventralization of the embryo. Alteration in ventral fates was demonstrated in the cuticle phenotypes where expansion of the denticle bands in segments Al-A5 was observed (Fig. 5D). Ventralization was also detected by staining the embryos for Fas III. Instead of the four to five rows of cells normally expressing Fas III, the expression in $\mathrm{T} 2$ and $\mathrm{T} 3$ was expanded to eight to ten rows of cells on each side of the midline (Fig. $5 E)$.

Finally, it was important to study the effect of overexpressing the Spitz constructs within the normal domain of DER activity in the ventral ectoderm. We therefore used the rho-GAL4 line in which the expression of Gal4 mirrors the early expression profile of $r h o$, and is restricted to eight cell rows on each side of the midline (data not shown). The UAS-mSpi and UAS-sSpi flies were crossed to rho-GAL4 flies, and the effects on expression of Otd were monitored. Again, the Spitz precursor did not alter the normal expression of Otd in the ventral-most one to two rows of cells (Fig. 5C). However, the secreted form induced a dramatic expansion of Otd expression, up to eight cell rows on each side of the midline (Fig. 5F). Because DER is crucial for cell fate determination in the ventral ectoderm, the ventralization observed following overexpression of secreted Spitz is consistent with hyperactivation of the DER pathway. Furthermore, these results demonstrate clearly that graded DER activity is normally responsible for generation of distinct cell fates within the ventral ectoderm. Spatially controlled processing of the Spitz precursor may provide the mechanism for defining the graded activation of DER.

\section{Possible effects of Rho and Star}

On the basis of genetic interactions it has been suggested that Rho and Star act as modulators of DER signaling. S2 cells do not express detectable levels of Rho and Star (Fig. 6). Thus, activation of DER by secreted Spitz can occur in the absence of these proteins. The establishment of a sensitive quantitative assay for the activation of the DER pathway by limiting Spitz concentrations may provide a basis to test the possible modification of DER signaling by Rho and Star. The single cell cloned S2:DER2f cells express sufficient basal levels of the DER type II protein, even in the absence of induction. This cell line was cotransfected with constructs expressing Rho and Star 

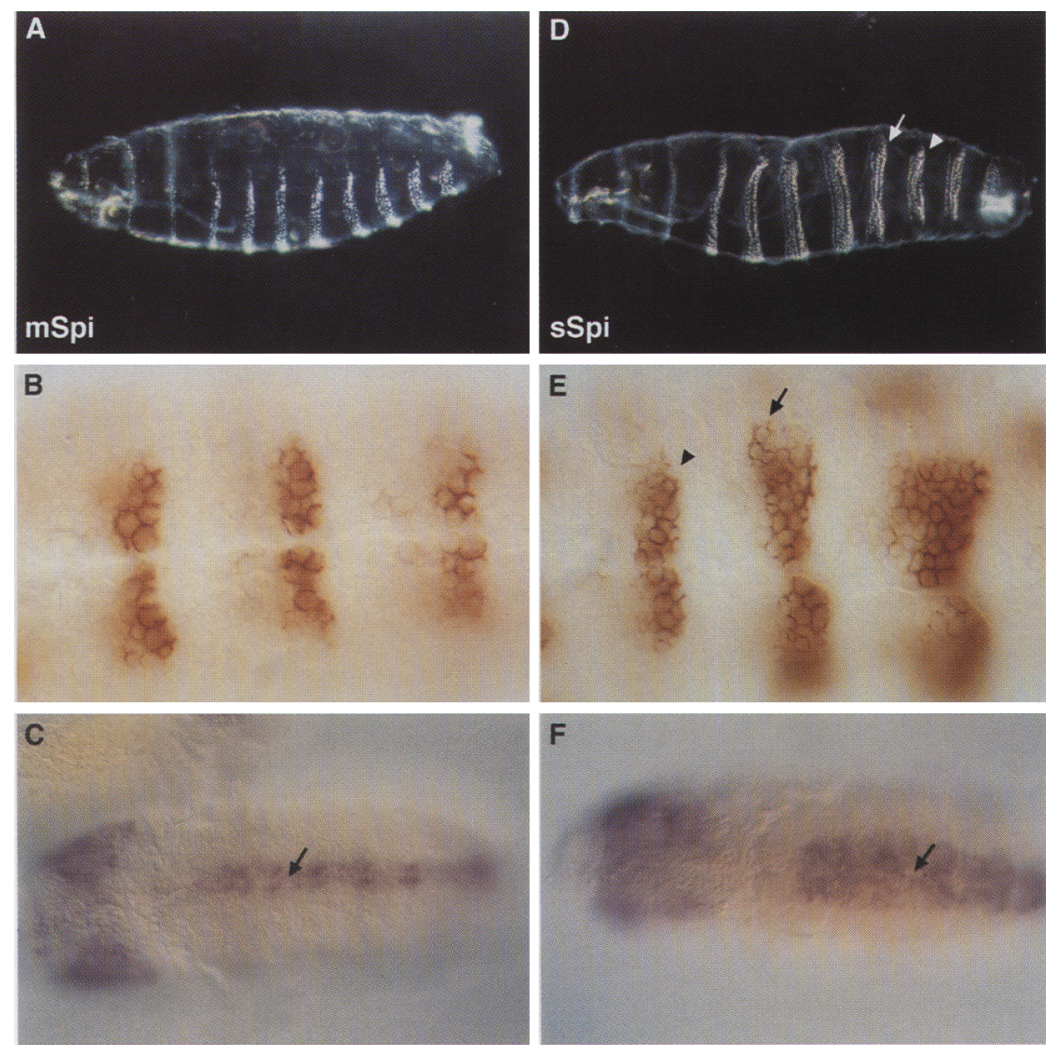

Figure 5. Expression of secreted Spitz in the embryo induces ventralization. The effects of ectopic expression of the Spitz precursor or the secreted Spitz were monitored in embryos. Induction of UAS- $m S$ pi by crossing to $\mathrm{Kr}-G A L 4$ flies resulted in partially penetrant embryonic lethality with no visible cuticle phenotype $(A)$ and did not affect the pattern of Fas III expression in the ventral ectoderm $(B)$. Induction of the same construct by rho-GAL4 did not alter the pattern of otd expression $(C)$. Only one to two cell rows on each side of the midline (arrow) express the marker. In contrast, induction of UAS-sSpi by $\mathrm{Kr}-G A L 4$ resulted in the expansion of the denticle bands in segments A1-A5 (D). A5 is marked by an arrow, and A6 by an arrowhead. The inducer is expressed only in T2-A4. The effect of sSpi on A5 as well may be accounted for by diffusion of the ligand. The same embryos show an expansion of Fas IIl staining in parasegments T2 and $\mathrm{T} 3(E)$. T2 is marked by an arrow and $\mathrm{T} 1$ by an arrowhead. Induction of UAS-sSpi by rho$G A L 4|F|$ resulted in the expansion of otd expres sion up to eight cell rows on each side of the midline (arrow). Embryos were stained at stage $11(7 \mathrm{hr}$ after egg laying). Anterior is to the left. under regulation of the HSP70 promoter, to generate the S2:D2RS cell line. Induction of Rho and Star following heat shock was observed within $1 \mathrm{hr}$ (Fig. 6).

MAPK is the final step in the cytoplasmic signaling of receptor tyrosine kinases (RTKs). Therefore, a possible effect of Rho or Star on the cytoplasmic components of the DER pathway should be reflected in the level or kinetics of MAPK activation. S2:D2RS cells were heatshocked and used after 1.5-2 hr, which was shown to be the optimal time for maximal accumulation of Rho and Star. To facilitate detection of modulation in MAPK ac-

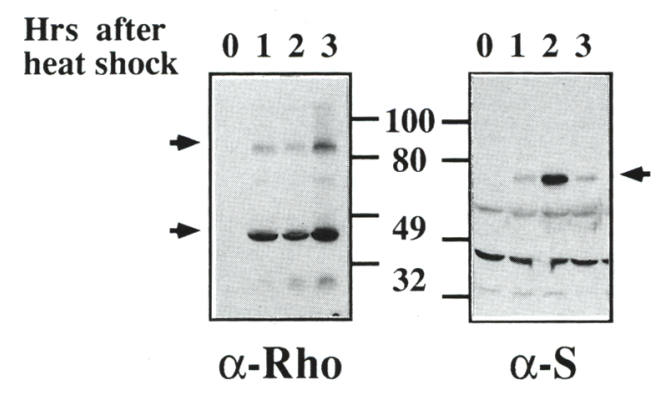

Figure 6. Expression of Rho and Star in S2:DER2f cells. S2:DER2f cells were cotransfected with constructs expressing Rho and Star under regulation of the HSP70 promoter. Following heat shock, extracts were prepared at different time points, and the level of Rho and Star was monitored by Western blotting. Note the appearance of Rho as monomers and dimers (arrows). The position of the Star protein is also shown by an arrow. tivity, the cells were incubated with the intermediate, 75-fold dilution of the Spitz-conditioned medium, and MAPK activity was assayed. No difference in the pattern of MAPK activation was observed, compared with the same cells without heat shock induction, or with the cells of the original DER-expressing line (Fig. 4A).

\section{Secreted Spitz is epistatic to rho or Star}

One way to account for the fact that expression of Rho or Star in S2 cells has no effect on the activation of DER by secreted Spitz is to suggest that they may normally facilitate processing of the Spitz precursor. To test this possibility, secreted Spitz expression was induced in rho ${ }^{\Delta 38}$ or Star ${ }^{I N 23}$ homozygous mutant embryos. rho or Star embryos do not show any expression of Fas III in the ventral ectoderm (Figs. 7A,B; M. Golembo and B.-Z. Shilo, in prep.). However, induction of the UAS-sSpi construct in the same mutant backgrounds resulted in broad expression of Fas III, in eight to nine cell rows on each side of the ventral midline (Figs. $7 \mathrm{C}, \mathrm{D}$ ). This pattern is identical to that obtained following induction of UAS-sSpi in wild-type embryos (Fig. 5E). Thus, once secreted Spitz is produced, the functions of Rho and Star are no longer necessary for the induction of ventral ectodermal cell fates.

\section{Discussion}

Genetic and phenotypic analyses of spitz mutants and the structural homology of Spitz to TGF- $\alpha$ strongly sug- 
Figure 7. Secreted Spitz is epistatic to rho or Star. Homozygous $r h o^{\Delta 38}(A)$ or $S^{I I N 23}(B)$ embryos show no expression of Fas III in the ventral ectoderm. However, induction of expression of secreted Spitz in homozygous rho mutant embryos by rho-GALA $(C)$ or in Star mutant embryos by 69B-GAL4, leads to ventralized embryos, as demonstrated by the expanded ectodermal expression pattern of Fas III (arrows).
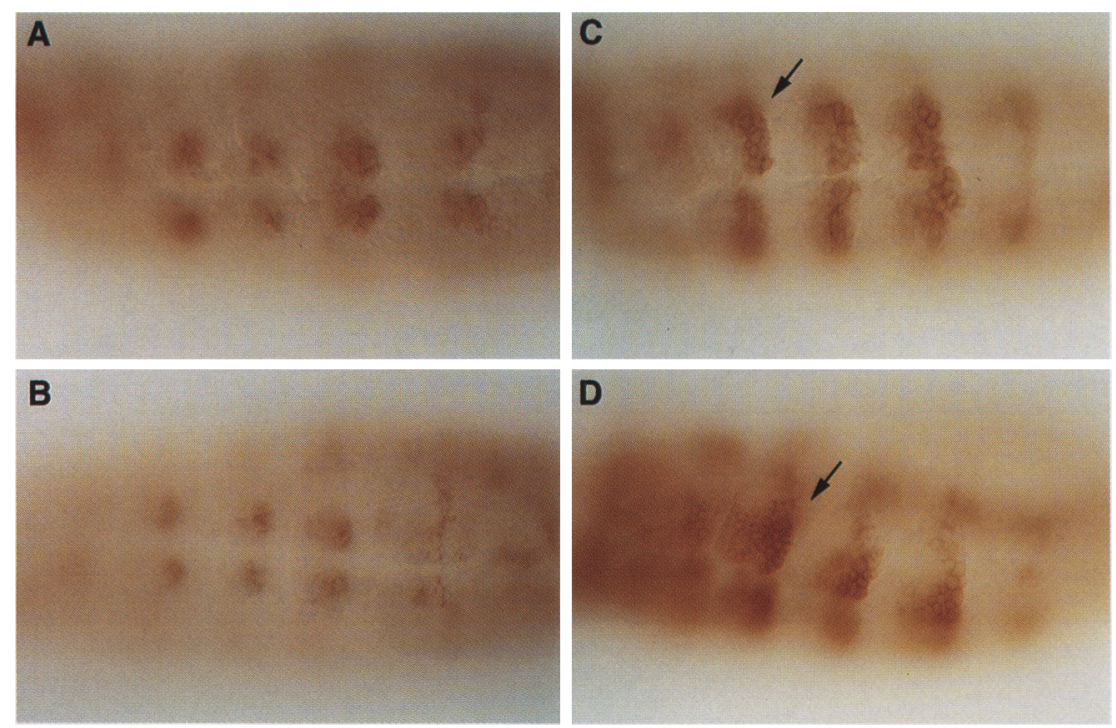

gested that it is a ligand for DER. This notion was tested experimentally. A cell culture assay for DER activation was established and used to demonstrate that the secreted form of Spitz is capable of triggering DER autophosphorylation and the downstream signaling pathway. Overexpression of secreted Spitz in the embryo leads to ventralization of the ectoderm, indicating that Spitz cleavage is a tightly regulated process which may control cell fate decisions in the ventral ectoderm by modulating the levels of DER activity.

\section{Activity of secreted Spitz}

Whereas the secreted form of Spitz was highly active, the membrane-associated form was inactive in our assays. The biological activity of the secreted form of Spitz was implied previously by the analysis of mosaic clones of homozygous mutant spitz cells in the eye disc (Freeman 1994). It is interesting to note that in the case of Boss, the ligand of Sevenless in the eye disc, the opposite situation was observed. Boss is produced as a protein with seven transmembrane domains. Only the membrane-associated form of the ligand can trigger Sevenless. Moreover, the secreted form functions as a competitive inhibitor of activation (Krämer et al. 1991).

TGF- $\alpha$-like proteins are produced, in many cases, as membrane-associated proteins. The precursors of TGF- $\alpha$, NDF, amphiregulin, heparin-binding EGF, the Heregulins, Spitz, Gurken, and Lin-3 were all shown to contain a transmembrane domain (Massagué and Pandiella 1993). The production of a secreted ligand requires processing of the precursor form, guided by rules that are not totally clear and could possibly differ between the various ligands. In addition, the identity of the most carboxy-terminal amino acids in the TGF- $\alpha$ precursor was shown to be crucial for ligand processing (Bosenberg et al. 1992). The possibility that some ligands would be functional in their membrane-associated form also ex- ists. It has been shown that membrane-anchored TGF- $\alpha$ can trigger the EGF receptor, although at a lower efficiency (Wong et al. 1989). Therefore, processing of the ligand precursor or presentation of the membrane-associated ligand may represent central regulatory steps.

\section{Spitz processing is tightly regulated}

The normal expression of the Spitz precursor in the ectoderm is uniform (Rutledge et al. 1992). The sensitivity of ventral ectoderm patterning to overexpression of the secreted Spitz protein therefore indicates that Spitz processing must be tightly regulated in vivo. The ventralization that was observed in the embryos is indicative of hyperactivation of the DER pathway.

Genetic interactions of mutations in the rho and Star genes with mutations in elements of the DER signaling pathway suggest that they act as modulators of DER signaling (Sturtevant et al. 1993; Raz and Shilo 1993; Noll et al. 1994; Freeman 1994). Following addition of limiting concentrations of secreted Spitz, we failed to detect any biological effects of Rho and Star on the signaling pathway of DER, suggesting that in S2 cells Rho and Star do not interact directly with DER or with downstream elements in the DER signaling pathway. These results may be accounted for by several explanations: The S2 cells may be lacking upstream or downstream components required for activation of Rho or Star. It is also possible that Rho and Star act in vivo to promote the presentation of the membrane-associated ligand to the receptor, a situation that has not been mimicked properly in the cell culture assay. Alternatively, Rho and Star may be activating an independent signaling pathway which converges with the DER pathway downstream to MAPK. However, we favor the suggestion that Rho or Star may participate normally in Spitz processing, to generate the biologically active, secreted form. The requirement for these proteins may thus be bypassed in the 
tissue culture assay by the presentation of secreted Spitz to the DER-expressing S2 cells. It is interesting to note that overexpression of Rhomboid in the embryo gave rise to ventralization (M. Golembo and B.-Z. Shilo, in prep.), similar to the situation observed following overexpression of secreted Spitz. The tight regulation of rho expression (Ip et al. 1992) may thus provide the cue for localized processing of Spitz in vivo.

The position of Rho and Star in the DER signaling pathway can also be tested by epistasis in embryos. The ventralizing effect of secreted Spitz was shown to be epistatic to the rho or Star mutant phenotypes, suggesting that these elements function upstream to the Spitz precursor, and may modulate its processing. A scheme of the possible order of action of the spitz group members and DER is presented in Figure 8.

The cells in which the Star or Rho proteins are required during development were identified in two cases: In the eye imaginal disc, Star was shown to be expressed in $\mathrm{R} 8, \mathrm{R} 2$, and $\mathrm{R} 5$ and to be required for their proper differentiation (Heberlein et al. 1993); and the presence of a functional spitz gene in R8 was shown to be obligatory for the differentiation of the other photoreceptor cells (Freeman 1994; Tio et al. 1994). Thus, in the eye disc both Star and Spitz are required in the R 8 cell. In the ovary both DER and Rho are expressed in the follicle cells, but the ligand, Gurken, is expressed as a membrane-anchored precursor in the oocyte (Neuman-Silberberg and Schüpbach 1993). It is not clear how Rho may affect the processing of Gurken. One possibility is that ligand processing occurs in more than one phase, where the initial stage may involve the formation of a secreted

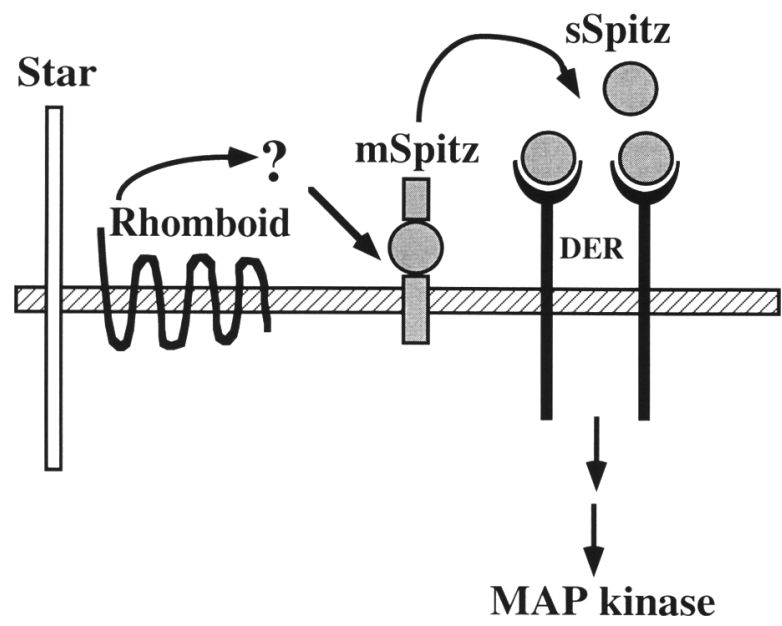

Figure 8. A model for the interaction of Spitz group proteins with the DER signaling pathway. The results presented in this paper suggest that processing of the Spitz membrane precursor to generate the secreted form is the rate-limiting step in the DER signaling pathway. This event may be regulated by the Rho and Star proteins, directly or indirectly, in the secretory vesicles or on the cell surface. Once secreted Spitz is produced, it will trigger DER and its downstream signaling pathway. The local amount of secreted Spitz that is available will determine the extent of DER activation, the level of MAPK activity, and the resulting ventral cell fate, accordingly. ligand, whereas subsequent steps /which may involve Rho) would contribute to further processing, to generate the active form of the ligand. Alternatively, Rho present on the membranes of the follicle cells may facilitate Gurken cleavage on the oocyte membrane.

Phenotypic analyses and genetic interactions suggest that Spitz may activate DER in several biological contexts, including the ventral embryonic ectoderm, the midline glial cells, the chordotonal organs, the wing disc, and the eye imaginal disc. However, additional ligands are clearly required to account for the wide repertoire of DER phenotypes. In the ovary, Gurken is the crucial element in the activation of DER signaling in the follicle cells (Neuman-Silberberg and Schüpbach 1993). In the eye disc an additional ligand has been postulated because Spitz is only expressed posterior to the morphogenetic furrow (Tio et al. 1994), whereas DER was also shown to be expressed and required for the proliferation of the cells throughout imaginal disc development (Zak and Shilo 1992; Xu and Rubin 1993|. Finally, it is possible that in some contexts the basal, nonactivated, level of DER autophosphorylation would also contribute to its biological activity. A relatively high basal level of DER autophosphorylation was detected when DER was overexpressed in the S2 cells, even in the absence of triggering by Spitz.

\section{Levels of DER activation dictate different cell fates}

Downstream elements in the DER signaling pathway that were identified genetically, were also shown to be expressed and functional in the S2 cells. Triggering of DER by Spitz resulted in association between DER and Drk. Consequently, the typical pattern of MAPK activation was also observed. The ability to follow DER autophosphorylation and MAPK activity after the addition of Spitz-conditioned medium, has allowed us to monitor the effect of low Spitz levels. Under limiting Spitz concentrations, we find a correlation between the Spitz dose and the maximal level of MAPK activation. This observation demonstrates that the DER signaling pathway can be activated at intermediate levels.

A possible biological implication is that the responding cells would be capable of monitoring the level or kinetics of MAPK activation, and will translate it into discrete cell fates, by generating different thresholds for their transcriptional responses. In rat $\mathrm{PC} 12$ cells it has been suggested that the different effects of nerve growth factor (NGF) or EGF on these cells may be accounted for by quantitative differences in the level and kinetics of MAPK activation (Dikic et al. 1994; Traverse et al. 1994). On the basis of a temperature-sensitive allele of the Drosophila MEK gene, it has been argued that different RTKs may elicit divergent responses driven by alterations in the strength of activation of the Ras pathway (Hsu and Perrimon 1994).

In the case of DER, in some instances its function is required in an all-or-none fashion. For example, the midline glial cells express DER and require its activity for proper differentiation. In other cases, however, DER is 
activated in a field of cells and may be responsible for an array of distinct cell fate determinations. Most notably, the dorsal follicle cells in an egg chamber receive an activating signal from a localized source of Gurken in the oocyte. The subsequent differentiation of these cells is not uniform. By utilizing a follicle enhancer trap marker, it was possible to show that the dorsal-anterior follicle cells directly above the Gurken source express high levels of the marker, whereas the more posterior follicle cells express lower levels of the marker. Expression of activated Raf in the follicle cells resulted in a strong expression of this marker in all cells (Brand and Perrimon 1994).

In the embryo, DER is required for determination of ventral ectodermal fates (Raz and Shilo 1993). It was not known, however, whether in this context DER is activated in a uniform or a graded manner. Within the ventral domain affected by DER, several distinct cell fates can be identified. For example, the ventral-most cells express both Otd and Fas III, whereas the more lateral cells express only Fas III. Hyperactivation of the DER pathway by overexpressing the secreted Spitz protein resulted in expansion of Otd expression. The ventral-most cell rows normally expressing Otd may thus differ from the more lateral cells expressing only Fas III, by the level of DER activation. In conclusion, discrete cell fates in the ventral ectoderm may be generated by graded activation of DER.

It is interesting to note that similar principles appear to be utilized for determination of ventral fates by the maternal Toll pathway and the zygotic DER pathway. In the maternal pathway, localized cleavage of Spätzle leads to graded activation of Toll, the Spätzle receptor (Chasan and Anderson 1993). Regulated processing of Spitz may similarly give rise to graded activation of DER. Future experiments would examine whether Rho and Star are involved in the spatial control of Spitz processing.

\section{Materials and methods}

Plasmids

The $\mathrm{pRmHa} 3$ metallothionein vector (Bunch et al. 1988) was used for generating DER and Spitz expression constructs. MtDER2, the type II DER expression construct, was composed of the DER cDNA subcloned as an EcoRI-PvuIl fragment in $\mathrm{pRmHa} 3$ (after removal and subsequent reinsertion of an internal BstEII fragment). For the type I DER construct (MtDERI), the $5^{\prime}$ EcoRI-BstEII fragment of MtDER2 was replaced by the corresponding type I fragment. The spitz cDNA was obtained from N. Perrimon (Harvard Medical School, Boston, MA). The full-length Spitz expression construct, Mtspi, was generated by inserting the HindIII-BgIII fragment of the cl-7 spitz cDNA (Rutledge et al. 1992) into pRmHa3, and for the secreted Spitz construct, a stop codon (TAG) was introduced by PCR in the putative cleavage site of Spitz at lysine-129. The 500-bp PCR product was subcloned into $\mathrm{pRmHa} 3$ digested with $B a m \mathrm{HI}$ and HincII, and the sequence was verified. The rho and Star cDNAs were subcloned into CasperHS, a Casper vector containing the HSP70 promoter and the HSP70 3 '-flanking sequences, and the resulting constructs were termed HS-rho and HS-Star, respectively. The 1100-bp DdeI fragment of rho was subcloned into the EcoRI site of CasperHS, and the $3.3-\mathrm{kb} S n a \mathrm{BI}-E c o \mathrm{RI}$ frag- ment of Star was also subcloned into the EcoRI site of CasperHS. The rho cDNA was obtained from E. Bier (University of California at San Diego, La Jolla), and the Star cDNA from A. Kolodkin (University of Califormia, Berkeley) and U. Baneriee (University of California, Los Angeles).

\section{Cell lines}

S2 Schneider cells were grown in Schneider's medium, supplemented with $10 \%$ fetal calf serum. The calcium phosphate precipitate method of transfection was used to generate stable cell lines. The S2:spi and S2:sspi cell lines were established by cotransfection of $\mathrm{pV} 8$, a plasmid conferring neomycin resistance with the Mtspi and Mtsspi plasmids respectively, followed by selection in $1 \mathrm{mg} / \mathrm{ml}$ of Geneticin G-4l8 (GIBCO). S2:sspi cells were used as a pool of transfected cells, whereas for $\mathrm{S} 2$ :spi, a homogeneous population of high expressors was required. S2:spi cells were therefore cloned by limiting dilution (Ashburner 1989), and the S2:spi4 clone was chosen for use in DER activation assays.

The MtDER1 and MtDER2 plasmids were cotransfected with the pV8 plasmid to generate the S2:DER1 and S2:DER2 cell lines, respectively. Both cell lines were subjected to limiting dilution cloning and the S2:DER2f and S2:DERIb cell lines were chosen for the experiments described below. In the S2:DER2f cell line, sufficient levels of the DER protein are expressed even in the absence of induction. It was therefore used as a constitutive DER-expressing cell line. For studying the effects of the Rho and Star proteins on DER activation, the S2:DER2f cells were cotransfected with pMK33 lobtained from D. Hogness, Stanford School of Medicine, CAl, a hygromycinresistance vector, accompanied by the HS-rho and HS-Star plasmids. After selection in $200 \mu \mathrm{g} / \mathrm{ml}$ of hygromycin B (Calbiochem|, the S2:D2RS cell line was established.

\section{Antibodies}

Anti-DER antibodies were generated by subcloning the cytoplasmic EcoRI fragment of DER into the pATH3 expression vector. The resulting TrpE-DER fusion protein was injected to guinea pig and the polyclonal serum was called gpct5. AntiSpitz antibodies were generated by introducing the secreted spitz PCR fragment into the pGEX2T expression vector. Polyclonal rabbit antibodies (Rbsspi) and a monoclonal antibody from rat (mAb Rtsspil were generated against the glutathione $S$-transferase $(G S T)$ secreted Spitz fusion protein. The anti-phosphotyrosine $\mathrm{mAb} 20.5$ is an affinity-purified ascites fluid from a monoclonal antibody raised against phosphotyrosine-keyhole limpet cyanin (KLH). Antibodies to the Rho protein (RbrhoNt) were generated by introducing the amino-terminal 630-bp EcoRI-BamHI fragment of rho cDNA into the pATH3 expression vector. The TrpE-Rho fusion protein was injected to rabbits and polyclonal sera were collected. Anti-Drk antibodies were received from T. Pawson (University of Toronto, Canada), and the anti-Star antibodies from $\mathrm{U}$. Baneriee.

\section{DER activation assay}

Induction of DER expression in the S2:DER1 or S2:DER2 cell lines by $700 \mu \mathrm{M} \mathrm{CuSO}_{4}$, the optimal concentration of the inducer (Bunch et al. 1988), resulted in high levels of expression and spontaneous autophosphorylation of the DER protein. However, when milder conditions of induction were tested, it was found that $3 \mathrm{hr}$ of induction by $60 \mu \mathrm{M} \mathrm{CuSO}_{4}$, resulted in sufficient levels of DER expression with very low levels of autophosphorylation. 
DER-expressing cells were seeded in 24-well plates $15 \times 10^{5}$ cells/well). DER expression was induced by $60 \mu \mathrm{M} \mathrm{CuSO}_{4}$, and the cells were washed in Schneider's medium and incubated with a secreted Spitz-conditioned medium (an S2:sspi medium collected $48 \mathrm{hr}$ after induction with $700 \mu \mathrm{M} \mathrm{CuSO}_{4}$ in serumfree medium). The cells were subsequently lysed in ice-cold RIPA buffer $\{50 \mathrm{~mm}$ Tris at $\mathrm{pH} 8.0,150 \mathrm{~mm} \mathrm{NaCl}, 1 \%$ Triton $\mathrm{X}-100,0.5 \%$ deoxycholate, $0.1 \%$ SDS, $1 \mathrm{~mm} \mathrm{Na} \mathrm{VO}_{4}, 5 \mathrm{~mm}$ $\mathrm{NaF}, 5 \mathrm{~mm}$ EDTA, $1 \mathrm{mM}$ PMSF, $1 \mathrm{~mm}$ benzamidine, $5 \mu \mathrm{g} / \mathrm{ml}$ of aprotinin, and $2 \mu \mathrm{g} / \mathrm{ml}$ leupeptin) for $20 \mathrm{~min}$, and the lysates were clarified by centrifugation and immunoprecipitated by the gpct5 anti-DER antibodies. Western blotting of the samples followed standard procedures and the blots were probed with the $\mathrm{mAB} 20.5$ anti-phosphotyrosine antibody.

For activation assays involving the membrane-associated Spitz, S2:spi4 cells induced to express Spitz by incubation with $700 \mu \mathrm{M} \mathrm{CuSO}_{4}$ for $24 \mathrm{hr}$ were used. S2:DER (1 or 2 ) cells were overlaid by the S2:spi 4 cells or membrane preparations of these cells. Alternatively, to ensure the proximity of DER and Spitz molecules, the S2:DER cells were mixed with a fivefold excess of $\mathrm{S} 2$ :spi 4 cells or the membrane preparations and spun for 3 $\mathrm{min}$ at $3000 \mathrm{rpm}$. After 5-10 min the cells were lysed and assayed as above.

The association of the DER and Drk proteins was observed by subjecting the cells after DER activation to a mild detergent lysis $(50 \mathrm{~mm}$ HEPES at $\mathrm{pH} 7.5,150 \mathrm{~mm} \mathrm{NaCl}, 5 \%$ glycerol, and $1 \%$ Triton X-100). After immunoprecipitation by anti-Drk antibodies and extensive washing, western blots of the samples were probed by mAb 20.5 antibodies, and gpct 5 antibodies to check for the presence of DER.

\section{Western blotting of the Rho protein}

Rho is a very hydrophobic protein. Incubating lysates of Rhoexpressing cells at $100^{\circ} \mathrm{C}$ with the protein sample buffer gave rise to very large aggregates that could not enter the resolving gel and were therefore detected in the interface between the stacking and resolving gels. However, when the cell lysates were incubated with the sample buffer at $37^{\circ} \mathrm{C}$ for $10 \mathrm{~min}$, the Rho protein was detected as a monomer. Even under these conditions, dimers and higher molecular weight aggregates were detected. The balance between the different forms was delicate and varied between experiments. Bands of degraded Rho protein were also commonly detected in these gels.

\section{MAPK assay}

MAPK activity was assayed as described previously (Seger et al. 1994). Briefly, cells were serum starved for $48 \mathrm{hr}$ in $5-\mathrm{cm}$ plates $15 \times 10^{6}$ cells/plate). At different intervals following incubation with secreted Spitz, the cells were washed with ice-cold PBS, scraped off the plates, and sonicated. Extracts were clarified by centrifugation and fractionated on DEAE-cellulose mini-columns. The columns were washed in low salt buffer $10.02 \mathrm{M}$ $\mathrm{NaCl}$ ), and MAPK was eluted with $0.22 \mathrm{M} \mathrm{NaCl}$. MAPK activity was determined by phosphate incorporation into MBP for 30 $\min$ at $30^{\circ} \mathrm{C}$.

To study the effects of Rho and Star on MAPK activation, the D2RS cells were heat-shocked twice for $30 \mathrm{~min}$ at $37^{\circ} \mathrm{C}$ with a 30-min interval, and the assays were performed $1.5-2 \mathrm{hr}$ after the second heat shock.

\section{$P$ constructs and fly strains}

The pUAS-mSpi construct was generated by introducing the 0.9-kb HindIII-BglII fragment of the cl-7 spitz cDNA plasmid into the pUAST vector (Brand and Perrimon 1993) digested with $E c O R I$ and BglII. The pUAS-sSpi construct was generated by introducing the secreted Spitz-encoding fragment as an $0.5-\mathrm{kb}$ EcoRI-KpnI fragment into pUAST digested with the same enzymes.

Transgenic flies were generated using the standard injection protocols. For the UAS $-m S p i$ flies, $1 \mathrm{mg} / \mathrm{ml}$ of pUAS $-m S p i$ and $0.3 \mathrm{mg} / \mathrm{ml}$ of the helper plasmid were used. In the case of the pUAS-sSpi plasmid, the same concentrations resulted in excessive lethality of the injected embryos $11 \%$ hatching from 2000 injected embryos), probably because of the transient expression. Injection of the same construct driven by the HSP70 promoter resulted in the lethality of all injected embryos (1500 embryos). We therefore reduced the concentration of pUAS-sSpi to 0.2 $\mathrm{mg} / \mathrm{ml}$ and obtained $7 \%$ hatching from 3500 injected embryos. The frequency of transgenic lines was $1 \%$ of the injected embryos for pUAS-mSpi, and $0.25 \%$ for pUAS-sSpi.

For the rescue of the spitz homozygous phenotype by the UAS-mSpitz construct, spitz ${ }^{\mathrm{OE} 92} / \mathrm{CyO}$; UAS-mSpi/ + flies were crossed to spitz ${ }^{O E 92} / C y O ; 69 \mathrm{~B}-G A L 4 /+$ flies. The homozygous spitz mutant embryos were identified by the absence of anti- $\beta-\mathrm{Gal}$ staining of the marked $\mathrm{CyO}$ balancer. For the sSpitz epistasis tests, UAS-sSpi/ +; rho ${ }^{ \pm 38} / T M 3$ flies were crossed to rho-GAL4/ +; rho ${ }^{238} / T M 3$ flies, and the homozygous rho mutant embryos identified by the absence of anti- $\beta$ Gal staining of the marked TM3 balancer. Similarly, $S^{I N 23}$ UAS-sSpi/CyO flies were crossed to $S^{I I N 23} / C y O$; 69B$G A L 4 /+$ flies, and the homozygous $S$ mutant embryos identified by the absence of anti- $\beta$-Gal staining of the marked $\mathrm{CyO}$ balancer.

\section{Induction and staining of embryos}

The following Gal4-expressing strains were used to induce the expression of the membrane associated and secreted forms of Spitz in embryos: $\mathrm{Kr} \cdot G A L 4$ (obtained from M. Leptin, University of Cologne, Germanyl is a balanced double insertion on the third chromosome. rho-GAL4 lobtained from M. Levine, University of California at San Diego, La Jolla) is a homozygous insertion on the second chromosome. 69B lobtained from A. Brand and N. Perrimon) is a homozygous insertion on the third chromosome (Brand and Perrimon 1993). The induced embryos were stained with anti-Fas III antibodies lobtained from T. Volk, Weizmann Institute of Science) or hybridized with an otd probe (obtained from R. Finkelstein, University of Pennsylvania, Philadelphial.

\section{Acknowledgments}

We thank N. Perrimon for generously providing the spitz cDNA clone, P. Olivier and T. Pawson for the Drk antibodies, E. Bier for the rhomboid cDNA, A. Kolodkin and U. Baneriee for the Star cDNA and antibodies, T. Volk for the Fas III antibodies, R. Finkelstein for the otd cDNA, A. Brand for the pUAST plasmid and 69B stock, M. Levine and M. Leptin for Gal4 stocks, N. Perrimon for the spitz strain, M. Freeman for the rho strain, C. Nüsslein-Volhard for the $S$ strain, and D. Hogness for the pMK33 plasmid. M. Golembo contributed to stimulating and critical discussions. We also acknowledge the excellent technical help of R. Leiserowitz and I. Weizman, and the contribution of $O$. Leitner to the production of antibodies. The work was supported by grants from the National Institutes of Health, the Council for Tobacco Research, the German Cancer Research Center (DKFZ), the Wolfson Fund and the Minerva Foundation to B.S.

The publication costs of this article were defrayed in part by 
payment of page charges. This article must therefore be hereby marked "advertisement" in accordance with 18 USC section 1734 solely to indicate this fact.

\section{References}

Ashburner, M. 1989. Drosophila a laboratory manual. Cold Spring Harbor Laboratory Press, Cold Spring Harbor, New York.

Baker, N.E. and G.M. Rubin. 1989. Effect on eye development of dominant mutations in Drosophila homologue of the EGF receptor. Nature 340: 150-153.

Baumann, P. and H. Skaer. 1993. The Drosophila EGF receptor homolog (DER) is required for malpighian tubule development. Development (Suppl.) 65-75.

Bier, E., L.Y. Jan, and Y.N. Jan. 1990. rhomboid, a gene required for dorsoventral axis establishment and peripheral nervous system development in Drosophila melanogaster. Genes \& Dev. 4: 190-203.

Biggs, W.H. III, K.H. Zavitz, B. Dickson, A. van der Straten, D. Brunner, E. Hafen, and S.L. Zipursky. 1994. The Drosophila rolled locus encodes a MAP kinase required in the Sevenless signal transduction pathway. EMBO /. 13: 1628-1635.

Biggs, W.H. III and S.L. Zipursky. 1992. Primary structure, expression, and signal-dependent tyrosine phosphorylation of a Drosophila homolog of extracellular signal-regulated kinase. Proc. Natl. Acad. Sci. 89: 6295-6299.

Bosenberg, M.W., A. Pandiella, and J. Massagué. 1992. The cytoplasmic carboxy-terminal amino acid specifies cleavage of membrane TGFa into soluble growth factor. Cell 71: 11571165.

Brand, A. and N. Perrimon. 1993. Targeted gene expression as a means of altering cell fates and generating dominant phenotypes. Development 118: 401-415.

1994. Raf acts downstream of the EGF receptor to determine dorsoventral polarity during Drosophila oogenesis. Genes \& Dev. 8: 629-639.

Brunner, D., N. Oellers, J. Szabad, W.H. Biggs III, S.L. Zipursky, and E. Hafen. 1994. A gain of function mutation in Drosophila MAP kinase activates multiple receptor tyrosine kinase signalling pathways. Cell 76: 875-888.

Buday, L. and J. Downward. 1993. Epidermal growth factor regulates $\mathrm{p} 21^{\text {ras }}$ through the formation of a complex of receptor, Grb2 adapter protein, and Sos nucleotide exchange factor. Cell 73: 611-620.

Bunch, T.A., Y. Grinblat, and L.S.B. Goldstein. 1988. Characterization and use of the Drosophila metallothionein promoter in cultured Drosophila melanogaster cells. Nucleic Acids Res. 16: 1043-1061.

Chasan, R. and K.V. Anderson. 1993. Maternal control of dorsalventral polarity and pattern in the embryo. In The Development of Drosophila melanogaster (ed. M. Bate and A. Martinez-Arias), pp. 387-424. Cold Spring Harbor Press, Cold Spring Harbor, New York.

Clark, S.G., M.J. Stern, and H.R. Horvitz. 1992. C. elegans cellsignalling gene sem- 5 encodes a protein with $\mathrm{SH} 2$ and $\mathrm{SH} 3$ domains. Nature 356: 340-344.

Clifford, R.J. and T. Schüpbach. 1990. Coordinately and differentially mutable activities of torpedo, the Drosophila melanogaster homolog of the vertebrate EGF receptor gene. Genetics 123: 771-787

Diaz-Benjumea, F.J. and A. Garcia-Bellido. 1990. Behaviour of cells mutant for an EGF receptor homologue of Drosophila in genetic mosaics. Proc. R. Soc. Lond. B 242: 36-44.

Diaz-Benjumea, F.J. and E. Hafen. 1994. The sevenless signal- ling cassette mediates Drosophila EGF receptor during epidermal development. Development 120: 569-578.

Dikic, I., J. Schlessinger, and I. Lax. 1994. PCl2 cells over expressing the insulin receptor undergo insulin-dependent neuronal differentiation. Curr. Biol. 4: 702-708.

Egan, S.E., B.W. Giddings, M.W. Brooks, L. Buday, A.M. Sizeland, and R.A. Weinberg. 1993. Association of Sos Ras exchange protein with Grb2 is implicated in tyrosine kinase signal transduction and transformation. Nature 363: 45-51.

Freeman, M. 1994. The spitz gene is required for photoreceptor determination in the Drosophila eye where it interacts with the EGF receptor. MOD 48: 25-33.

Heberlein, U., I.K. Hariharan, and G.M. Rubin. 1993. Star is required for neuronal differentiation in the Drosophila retina and displays dosage-sensitive interactions with Ras1. Dev. Biol. 160: 51-63.

Hill, R.J. and P.W. Sternberg. 1992. The gene lin-3 encodes an inductive signal for vulval development in C. elegans. $\mathrm{Na}$. ture 358: $470-476$.

Hsu, J.-C. and N. Perrimon. 1994. A temperature-sensitive MEK mutation demonstrates the conservation of the signaling pathways activated by receptor tyrosine kinases. Genes \& Dev. 8: 2176-2187.

Ip, Y.T., R.E. Park, D. Kosman, E. Bier, and M. Levine. 1992. The dorsal gradient morphogen regulates stripes of rhomboid expression in the presumptive neuroectoderm of the Drosophila embryo. Genes \& Dev. 6: 1728-1739.

Klaes, A., T. Menne, A. Stollewrek, H. Scholz, and C. Klämbt. 1994. The Ets transcription factors encoded by the Drosophila gene pointed direct glial cell differentiation in the embryonic CNS. Cell 78: 149-160.

Klämbt, C. 1993. The Drosophila gene pointed encoded two ets like proteins which are involved in the development of the midline glia cells. Development 117: 163-176.

Klämbt, C., R. Jacobs, and C.S. Goodman. 1991. The midline of the Drosophila central nervous system: A model for the genetic analysis of cell fate, cell migration, and growth cone guidance. Cell 64: 801-815.

Kolodkin, A.L., A.T. Pickup, D. Lin, C.S. Goodman, and U. Baneriee. 1994. Characterization of Star and its interactions with sevenless and EGF receptor during photoreceptor cell development in Drosophila. Development 120: 1731-1745.

Krämer, H., R.L. Cagan, and S.L. Zipursky. 1991. Interaction of bride of sevenless membrane-bound ligand and the sevenless tyrosine-kinase receptor. Nature 352: 207-212.

Li, N., A. Batzer, R. Daly, V. Yainik, E. Skolnik, P. Chardin, D. Bar-Sagi, B. Margolis, and I. Schlessinger. 1993. Guaninenucleotide-releasing factor hSos l binds to Grb2 and links receptor tyrosine kinases to Ras signalling. Nature 363: 8588.

Livneh, E., L. Glazer, D. Segal, J. Schlessinger, and B.-Z. Shilo. 1985. The Drosophila EGF receptor homolog: conservation of both hormone binding and kinase domains. Cell 40: 599607.

Lowenstein, E.J., R.J. Daly, A.B. Batzer, W. Li, B. Margolis, R. Lammers, A. Ullrich, E.Y. Skolnik, D. Bar-Sagi, and J. Schlessinger. 1992. The $\mathrm{SH} 2$ and $\mathrm{SH} 3$ domain-containing protein GRB2 links receptor tyrosine kinases to ras signaling. Cell 70: $431-442$.

Lu, X., T.-B. Chou, N.G. Williams, T. Roberts, and N. Perrimon. 1993. Control of cell fate determination by $21^{\text {ras }} /$ Ras 1 , an essential component of torso signaling in Drosophila. Genes \& Dev. 7: 621-632.

Massagué, J. and A. Pandiella. 1993. Membrane-anchored Growth Factors. Annu. Rev. Biochem. 62: 515-541. 
Mayer, U. and C. Nüsslein-Volhard. 1988. A group of genes required for pattern formation in the ventral ectoderm of the Drosophila embryo. Genes \& Dev. 2: 1496-1511.

Melnick, M.B., L.A. Perkins, M. Lee, L. Ambrosio, and N. Perrimon. 1993. Developmental and molecular characterizations of mutations in the Drosophila raf serine-threonine kinase. Development 118: 127-138.

Neuman-Silberberg, F.S. and T. Schüpbach. 1993. The Drosophila dorsoventral patterning gene gurken produces a dorsally localized RNA and encodes a TGF $\alpha$-like protein. Cell 75: 165-174.

- 1994 . Dorsoventral axis formation in Drosophila depends on the correct dosage of the gene gurken. Development 120: 2457-2463.

Noll, R., M.A. Sturtevant, R.R. Gollapudi, and E. Bier. 1994. New functions of the Drosophila rhomboid gene during embryonic and adult development are revealed by a novel genetic method, enhancer piracy. Development 120: 23292338.

Olivier, J.P., T. Raabe, M. Henkemeyer, B. Dickson, G. Mbamalu, B. Margulis, J. Schlessinger, E. Hafen, and T. Pawson. 1993. A Drosophila SH2-SH3 adapter protein implicated in coupling the sevenless tyrosine kinase to an activator of ras guanine nucleotide exchange, Sos. Cell 73: 179-191.

Patel, N.H., P.M. Snow, and C.S. Goodman. 1987. Characterization and cloning of fasciclin III: A glycoprotein expressed on subset of neurons and axon pathways in Drosophila. Cell 48: $975-988$.

Price, J.V., R.J. Clifford, and T. Schüpbach. 1989. The maternal ventralizing locus torpedo is allelic to faint little ball, an embryonic lethal, and encodes the Drosophila EGF receptor homolog. Cell 56: 1085-1092.

Raz, E. and B.-Z. Shilo. 1992. Dissection of the faint little ball $(f l b)$ phenotype: Determination of the development of the Drosophila central nervous system by early interactions in the ectoderm. Development 114: 113-123.

- 1993. Establishment of ventral cell fates in the Drosophila embryonic ectoderm requires DER, the EGF receptor homolog. Genes \& Dev. 7: 1937-1948.

Rogge, R.D., C.A. Karlovich, and U. Banerjee. 1991. Genetic dissection of a neurodevelopmental pathway: Son of sevenless functions downstream of the sevenless and EGF receptor tyrosine kinases. Cell 64: 39-48.

Rozakis-Adcock, M., R. Fernley, J. Wade, T. Pawson, and D. Bowtell. 1993. The SH2 and SH3 domains of mammalian Grb2 couple the EGF receptor to the Ras activator mSosl. Nature 363: 83-85.

Ruohola-Baker, H., E. Grell, T.-B. Chou, D. Baker, L.Y. Jan, and Y.N. Jan. 1993. Spatially localized Rhomboid is required for establishment of the dorsal-ventral axis in Drosophila oogenesis. Cell 73: 953-966.

Rutledge, B.J., K. Zhang, E. Bier, Y.N. Jan, and N. Perrimon. 1992. The Drosophila spitz gene encodes a putative EGF-like growth factor involved in dorsal-ventral axis formation and neurogenesis. Genes \& Dev. 6: 1503-1517.

Schejter, E.D. and B.-Z. Shilo. 1989. The Drosophila EGF receptor homolog (DER) gene is allelic to faint little ball, a locus essential for embryonic development. Cell 56: 1093-1104.

Schejter, E.D., D. Segal, L. Glazer, and B.-Z. Shilo. 1986. Alternative $5^{\prime}$ exons and tissue-specific expression of the Drosophila EGF receptor homolog transcripts. Cell 46: 1091-1101.

Seger, R., D. Seger, A.A. Reszka, E.S. Munar, H. Eldar-Finkelman, G. Dobrowolska, A.M. Jensen, J.S. Campbell, E.H. Fischer, and E.G. Krebs. 1994. Over-expression of Mitogen-Activated Protein Kinase Kinase (MAPKK) and its mutants in NIH-3T3 cells: Evidence that MAPKK's involvement in cel- lular proliferation is regulated by phosphorylation of serine residues in its kinase subdomains VII and VIII. I. Biol. Chem. 269: 25699-25709.

Simon, M.A., D.D.L. Bowtell, G.S. Dodson, T.R. Laverty, and G.M. Rubin. 1991. Ras1 and a putative guanine nucleotide exchange factor perform crucial steps in signaling by the sevenless protein tyrosine kinase. Cell 67: 701-716.

Simon, M.A., G.S. Dodson, and G.M. Rubin. 1993. An SH3-SH2$\mathrm{SH} 3$ protein is required for $\mathrm{p} 21^{\text {Ras1 }}$ activation and binds to sevenless and Sos proteins in vitro. Cell 73: 169-177.

Sturtevant, M.A., M. Roark, and E. Bier. 1993. The Drosophila rhomboid gene mediates the localized formation of wing veins and interacts genetically with components of the EGF-R signaling pathway. Genes \& Dev. 7: 961-9734.

Tio, M., C. Ma, and K. Moses. 1994. spitz, a Drosophila homolog of transforming growth factor-a, is required in the founding photoreceptor cells of the compound eye facets. MOD 48: 13-23.

Traverse, S., K. Seedorf, H. Paterson, C.J. Marshall, P. Cohen, and A. Ullrich. 1994. EGF triggers neuronal differentiation of PC1 2 cells that overexpress the EGF receptor. Curr. Biol. 4: 694-701.

Ullrich, A. and J. Schlessinger. 1990. Signal transduction by receptors with tyrosine kinase activity. Cell 61: 203-212.

Wieschaus, E., N. Perrimon, and R. Finkelstein. 1992. orthoden ticle activity is required for development of medial structures in larval and adult epidermis of Drosophila. Development 115: 801-811.

Wong, S.T., L.F. Winchell, B.K. McCune, H.S. Earp, J. Teixidó, J. Massagué, B. Herman, and D.C. Lee. 1989. The TGF- $\alpha$ precursor expressed on the cell surface binds to the EGF receptor on adjacent cells, leading to signal transduction. Cell 56: 495-506.

$\mathrm{Xu}, \mathrm{T}$. and G.M. Rubin. 1993. Analysis of genetic mosaics in the developing and adult Drosophila tissues. Development. 117: 1223-1236.

Zak, N.B. and B.-Z. Shilo. 1992. Localization of DER and the pattern of cell divisions in wild-type and Ellipse eye imaginal discs. Dev. Biol. 149: 448-456.

Zak, N.B., R.J. Wides, E.D. Schejter, E. Raz, and B.-Z. Shilo. 1990. Localization of the DER/flb protein in embryos: Implications on the faint little ball lethal phenotype. Develop. ment 109: 865-874. 


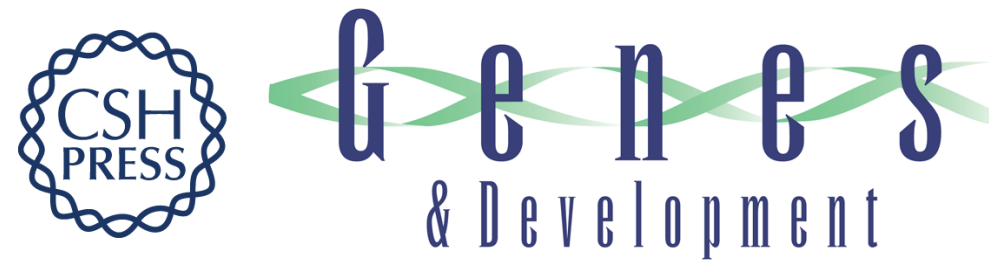

\section{Secreted Spitz triggers the DER signaling pathway and is a limiting component in embryonic ventral ectoderm determination.}

R Schweitzer, M Shaharabany, R Seger, et al.

Genes Dev. 1995, 9:

Access the most recent version at doi:10.1101/gad.9.12.1518

References This article cites 59 articles, 22 of which can be accessed free at:

http://genesdev.cshlp.org/content/9/12/1518.full.html\#ref-list-1

License

Email Alerting

Service

Receive free email alerts when new articles cite this article - sign up in the box at the top right corner of the article or click here.

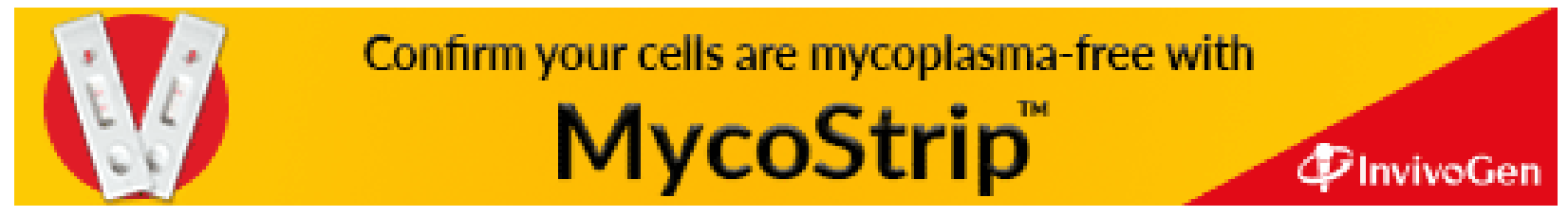

